\title{
Do Ministério Público como Superego da Sociedade: design institucional e legitimidade na atuação judicial e extrajudicial
}

\section{The Prosecution Service as Superego of Society: institutional design and legitimacy in judicial and extrajudicial proceedings}

\author{
Rafael de Oliveira Costa \\ Escola Superior do Ministério Público do Estado de São Paulo, São Paulo - SP, Brasil \\ University of California, Berkeley - CA, Estados Unidos
}

Resumo: O presente artigo pretende analisar a expansão da função juspolítica protagonizada pelo Ministério Público sob o marco teórico de Ingeborg Maus, em decorrência da recente projeção da moralidade pública na função exercida por Promotores/Procuradores de Justiça. Trata-se de pesquisa que faz uso de raciocínio hipotético-dedutivo, valendo-se de dados de natureza primária e secundária, permitindo concluir que, para evitar o arbítrio cerceador da soberania popular, o Ministério Público adote um novo design institucional que potencialize a sua atuação, com foco na preparação para o exercício eficiente da condição de superego da sociedade.

Palavras-chave: Design Institucional do Ministério Público. Superego da Sociedade. Expansão da Função Juspolítica.

\begin{abstract}
This article analyzes the expansion of the juspolitical function carried by Prosecutors under the theoretical framework of Ingeborg Maus. It uses hypothetical-deductive reasoning, drawing on data from primary and secondary nature, concluding that, to avoid arbitrariness restrictions of popular sovereignty, it is indispensable that the Prosecution Service adopts a new institutional design, enhancing its performance by focusing on the efficient exercise of the role of superego of society.
\end{abstract}

Keywords: Institutional Design. Superego of Society. Expansion of Juspolitical Function.

Recebido em: 06/11/2016

Revisado em: 10/04/2017

Aprovado em: 20/05/2017 


\section{Introdução}

Com o advento da Constituição de 1988, o Ministério Público passou a ser não apenas o titular da ação penal pública, mas a desempenhar outras funções essenciais para a defesa dos interesses da sociedade. Como exemplo, o Parquet passou a ser responsável por zelar pelo efetivo respeito dos Poderes Públicos e dos serviços de relevância pública, a promover o inquérito civil e a ação civil pública, a defender judicialmente os direitos e interesses das populações indígenas, a exercer o controle externo da atividade policial, entre outras atribuições (BRASIL, 1988, art. 129).

Essa alteração no campo normativo, contudo, tem implicado na modificação do papel social exercido pelo Ministério Público. Segundo entende-se, a intensa atuação na defesa dos direitos coletivos, especialmente na seara da improbidade administrativa, tem levado ao aumento da confiança da população na instituição e, consequentemente, à projeção pela sociedade da moralidade pública na função exercida por Promotores/Procuradores de Justiça ${ }^{1}$. O presente estudo pretende, nesse contexto, traçar os primeiros passos na árdua análise da expansão da função juspolítica protagonizada pelo Ministério Público sob a égide do conceito psicanalítico de imago paterna, em conformidade com a proposta de Ingeborg Maus (2002).

No intuito de evitar superficialismos e primar pela objetividade, faz-se indispensável, primeiramente, atentar para a função de superego desempenhada pelo Ministério Público para, então, nos debruçar sobre o design institucional desejado para a instituição.

A seguir será vista a concretização de nosso plano de estudos.

\footnotetext{
1 A título de exemplo, em recente diagnóstico realizado pela Praxian Business \& Marketing Specialists e disponibilizado pelo http://www.justocantins.com.br/, constatouse que a população possui a percepção de que o CNMP e o MP são "muito importantes para a Sociedade" e a maioria dos entrevistados vinculou a atuação do Ministério Público aos ideais de justiça, fiscalização e combate à corrupção. Além disso, a pesquisa Índice de Confiança na Justiça (disponível em: <http://bibliotecadigital.fgv.br/dspace/bitstream/ handle/10438/10282/Relat\%C3\%B3rio\%20ICJBrasil\%202\%C2\%BA\%20e\%20\%20 3\%C2\%BA\%20Trimestre\%20-\%202012.pdf?sequence=1>) realizada pela Fundação Getúlio Vargas, revelou que o Ministério Público é a terceira instituição que recebe a maior confiança da sociedade.
} 


\section{Do Ministério Público como Superego da Sociedade}

Hodiernamente, o Ministério Público passou a desempenhar tarefas que diversas vezes excedem suas atribuições e que não lhes são, ao menos sob a égide da concepção clássica de separação dos poderes, precípuas.

A expressão "Estado Democrático de Direito" não significa que Promotores e Procuradores apenas apliquem o Direito "preexistente" (SHAPIRO, 1994, p. 155-156). O Ministério Público, especialmente ao propor demandas ou resolver conflitos por meio da atuação extrajudicial, também cria o Direito. O paradoxo, contudo, está no fato de que, embora criem o Direito, Promotores e Procuradores normalmente não assumem fazê-lo (SHAPIRO, 1994, p. 155-56), sustentando serem parte de uma "instituição peculiar" e que "segue os ditames constitucionais e legais".

Contudo, o Ministério Público exerce parcela da autoridade política do Estado, embora a natureza política dessa atividade nada tenha a ver com o exercício de atividade "política partidária". Isso porque a condição de agente político, a "filltragem" das circunstâncias fáticas no momento de ajuizamento de demandas judiciais e a função "criadora" que vem sendo desempenhada pelos feitos coletivos ultrapassam a visão do processo como "um bloco de papel", compreendendo-o como fruto pulsante da vida em julgamento, de modo a exigir uma nova forma de atuar de Promotores e Procuradores de Justiça.

Assim, sob o argumento de se manter a ordem e a credibilidade na Justiça, os membros do Ministério Público têm se imiscuído cada vez mais no âmbito tradicionalmente demarcado para o exercício da função política. ${ }^{2}$ Temas que relacionam Direito e Política têm sido recorrentes

\footnotetext{
${ }^{2}$ Não existe consenso na doutrina acerca da distinção entre Direito e Política. Dentre as mais respeitadas proposições teóricas acerca do tema e de buscando ir além da análise de Ingeborg Maus realizada no presente trabalho, encontra-se a proposta de Niklas Luhmann (1990). Segundo Luhmann, o sistema do Direito é o conjunto de todas as comunicações produzidas na sociedade que se refiram ao Direito. Utiliza o autor a "regra de atribuição", que permite indicar se uma comunicação possui referência ao Direito. Essa comunicação se dá por meio de um código binário que, no sistema do Direito, é baseado na oposição lícito/ilícito (LUHMANN, 1994, p. 92). O código, então, garante a autonomia do sistema do Direito, a sua diferença em relação ao seu ambiente, o seu fechamento operacional
} 
nas sessões dos tribunais em razão das demandas coletivas ajuizadas pelo Ministério Público. A título de exemplo, a ação civil pública, como instrumento idôneo e apto a viabilizar a concretização de políticas públicas, torna cada vez mais necessária a revisão da teoria clássica da separação dos poderes em razão da intervenção do Ministério Público em temáticas

(LUHMANN, 1998). Por mais paradoxal que possa parecer, o fechamento operacional do sistema em Luhmann permite a sua abertura cognitiva e, desse modo, o Direito se porta como um sistema aberto para as demandas sociais, que podem vir de qualquer outro sistema (Política, Economia, entre outros) (LUHMANN, 1985).

O sistema da Política possui estrutura similar e também exerce uma função que o diferencia no interior da sociedade, ao formular decisões que vinculam a coletividade por meio do código situação/oposição. Assim, a diferenciação entre Direito e Política não significa o isolamento desses dois sistemas. Existe um canal de comunicação entre eles, que segue os limites traçados pela Constituição. A Constituição, na modernidade, surge como o meio adequado para a comunicação entre a Política e o Direito, fornecendo "os critérios de organização Política do poder e os critérios de geração do Direito" (CORSI, 2001, p. 173). Em princípio, o Legislativo, o Judiciário e o Ministério Público desempenham atribuições diversas e bem definidas. O Legislativo se encontra imerso em um contexto com um alto grau de complexidade, em que é vasto o plexo de matérias que se pode tornar objeto de seleção/decisão. Daí a necessidade de uma programação teleológica, própria da produção legislativa, canalizando o desejo de mudança do Direito vigente (LUHMANN, 1985, p. 34-42). A programação condicional, tipicamente utilizada na aplicação das leis pelo Judiciário e pelo Ministério Público, diverge diametralmente desse estado de coisas. Ela assume uma relação de se/então, ou seja, ocorrida uma hipótese, tem-se uma determinada consequência (CORSI, 2001, p. 173).

Devemos ressaltar que essa associação entre programação teleológica e Poder Legislativo, de um lado, e programação condicional e Poder Judiciário/Ministério Público, de outro, não se dá de forma hermética. É claro que o Judiciário e o Ministério Público operam com programações teleológicas, como acontece com os princípios constitucionais ou com as normas classificadas pela doutrina constitucional brasileira de programáticas. O que se pretende deixar claro, contudo, é o primado da atuação de cada uma das espécies de programação nas diferentes instituições. No Legislativo, há um primado operacional de programações teleológicas. No Judiciário/Ministério Público, ao contrário, prevalecem as programações condicionais. Assim, é possível concluir que: "No transcurso do processo histórico de afirmação do constitucionalismo, o novo telos jurídicocivilizacional do Ocidente se configurado em torno da Constituição como referencial de fundação, preservação, validação, legitimação, dinamização e atualização do sentido e do alcance do senso de juridicidade/antijuridicidade do Direito. E, ao longo das fases do constitucionalismo, as normas, os atos e as omissões passaram a ser aferíveis, no Direito, pela sua adequação ou inadequação com o senso de juridicidade/antijuridicidade decorrente da Constituição. ” (OLIVEIRA, 2013, p. 230) 
até então afetas à agenda política (v.g., tratamentos de saúde, implementação de políticas públicas na seara da infância e juventude, controle da qualidade da educação, entre outros).

Desse modo, o Ministério Público vem se tornando - juntamente com o Poder Judiciário - o último reduto político-moral da sociedade. É o que Ingeborg Maus convencionou chamar de "superego da sociedade órfã" no contexto da expansão do papel dos atores judiciais (MAUS, 2002, p. 186-187). A instituição exsurge com novas atribuições e competências que até então não lhe eram afeitas, aumentando progressivamente seu espaço de atuação, num movimento em que procura substituir funcionalmente a figura da imago paterna, responsável por ditar os valores morais da sociedade, que o Executivo e o Judiciário até então desempenharam (MAUS, 2002, p. 186-187).

Com efeito, a figura do "pai" desempenha o papel de "superego" da sociedade, visto que esta última encontra-se carente de um órgão central que fixe os "valores socialmente adequados" (MAUS, 2002, p. 186-187). Se por um lado percebe-se a descrença no Executivo e no Judiciário como concretizadores dos direitos fundamentais, a ampliação do papel exercido pelo Ministério Público brasileiro implica na transferência de parcela do ônus moral da sociedade, passando a atuar como "superego". A título de exemplo, pode-se mencionar a recente rejeição da Proposta de Emenda Constitucional n. 37, que acrescentaria o $\S 10$ ao artigo 144 da Constituição Federal, para definir a competência exclusiva para a investigação criminal pelas polícias federal e civis dos Estados e do Distrito Federal. ${ }^{3}$

O que se observa, portanto, é a ascensão do Ministério Público ${ }^{4}$ à qualidade de responsável pela moral na sociedade brasileira (MAUS,

\footnotetext{
${ }^{3}$ Conforme ressaltado anteriormente o Ministério Público está entre as três instituições mais confiáveis e honestas para a população brasileira, de acordo com pesquisa realizada pela Fundação Getúlio Vargas.

${ }^{4} \mathrm{O}$ embate pela condição de superego entre o Ministério Público e o Poder Judiciário pode ser facilmente percebido com a edição da Súmula 34, pelo Conselho Superior do Ministério Público do Estado de São Paulo. Com efeito, dispõe o enunciado que: "O Conselho Superior homologará arquivamento de inquéritos civis ou assemelhados cujo objeto autorize apenas a propositura de ação de reparação de danos ao erário, nos termos do art. $5^{\circ}$ da Lei 8429/92, quando, cumulativamente (1) o prejuízo não alcançar
} 
2002, p. 192). Por meio da introdução de "pontos de vista de valores" na argumentação e com ampliação dos limites do processo coletivo, confere-se não só maior grau de legitimação - imunizando as manifestações e decisões contra qualquer crítica que possa advir da sociedade -, como também acaba por desvincular o Ministério Público de amarras legais que poderiam garantir a conformidade da decisão com os anseios sociais.

expressão econômica relevante, assim entendido aquele que não seja superior ao previsto no art. 20 da Lei Federal n. 10.522/02; (2) houver prova de que o órgão do Ministério Público tenha comunicado o co-legitimado para a propositura da ação de ressarcimento, transmitindo os elementos de prova necessários a tal finalidade". A edição do enunciado veio embasada na conhecida sobrecarga de trabalho na área dos interesses difusos e no argumento de que é indispensável a racionalização do serviço para alcançar maior eficácia na atividade ministerial. Para tanto, buscou-se consignar que, nos casos de danos ao erário de pequena expressão econômica, a atuação do Ministério Público deve voltarse para o zelo de que a pessoa jurídica lesada tome as providências necessárias para o ressarcimento. Ocorre, no entanto, que o entendimento vem contrapor jurisprudência do Superior Tribunal de Justiça, no sentido que não se aplica o princípio da insignificância às hipóteses de improbidade administrativa. Vejamos o teor do julgado: "Se o bem jurídico protegido pela Lei de Improbidade é, por excelência, a moralidade administrativa, desarrazoado falar em aplicação do princípio da insignificância às condutas consideradas imorais pelo próprio magistrado. Não existe improbidade administrativa significante e improbidade administrativa insignificante. O que há é irregularidade insignificante (e, por isso, não constitui improbidade) e irregularidade significante (e, por isso, improbidade administrativa). No campo dos valores principiológicos que regem a Administração Pública, não há como fiscalizar a sua obediência com calculadora na mão, expressando-os na forma de reais e centavos. Logo, o princípio da insignificância não se presta para, após o juízo positivo de improbidade, exonerar, por inteiro e de forma absoluta, o infrator da aplicação das sanções - até da multa civil - previstas na Lei. Nesse âmbito, outros aspectos precisam ser levados em conta. A insignificância, como regra, exclui a tipicidade da conduta. Ora, no Direito da Improbidade Administrativa a marca é a tipicidade aberta, a começar pelo próprio sentido de moralidade administrativa. A Lei de Improbidade não lista, nem descreve, em numerus clausus, as condutas e tipos puníveis, ao contrário do que o fazem o Código Penal e as normas que prevêem ilícitos administrativos e disciplinares. Nem poderia fazê-lo, pois o legislador não teria como antecipar exaustivamente todas as ações contrárias à boa Administração." (REsp 769317/AL, Rel. Ministro GILSON DIPP, QUINTA TURMA, julgado em 07/03/2006, DJ 27/03/2006 p. 324, grifei) (REsp n. 892.818 - RS - Min. HERMAN BENJAMIN - 10/02/2010). Esse conflito reflete o delicado equilíbrio dinâmico que vem surgindo no diálogo Ministério Público / Poder Judiciário, diante da disputa pela condição de superego da sociedade. 
Assim, enriquecido por pontos de vista morais, o âmbito das "proibições" legais pode ser arbitrariamente estendido ao campo extrajurídico das esferas de liberdade. Somente a posteriori, por ocasião de um processo legal, é que o cidadão experimenta o que lhe foi "proibido", aprendendo a deduzir para o futuro o "permitido" (extremamente incerto) a partir das decisões dos tribunais. Os espaços de liberdade anteriores dos indivíduos se transformam então em produtos de decisão judicial fixados caso a caso. (MAUS, 2002, p. 186-187)

Com isso, a moral torna-se produto da interpretação do Promotor de Justiça. E mais: a parcial "absorção" da Ética pelo discurso jurídico adotado pelos membros da instituição busca imunizar a atividade judicial e extrajudicial do Ministério Público da crítica moral a que deveria se sujeitar (MAUS, 2002).

Frise-se que, ao contrário do que ocorre na Alemanha - país no qual Maus vislumbra o Judiciário como "superego" da sociedade -, no Brasil, o Ministério Público, atuando como responsável pela "filtragem" das principais demandas coletivas levadas ao conhecimento do Poder Judiciário - especialmente na seara da improbidade administrativa - e contando com amplo apoio popular, tornou-se verdadeiro órgão de confiança da sociedade, dizendo, a partir de um juízo de violação ao ordenamento - e consequente propositura de demandas, celebração de termos de ajustamento de conduta ou expedição de recomendações - aquilo que é ou não honesto, probo ou moralmente adequado. Assim, na condição de representante da sociedade e fiscal do cumprimento das leis, a instituição passou a ter a função de superego. As medidas adotadas por Promotores e Procuradores, embasadas em argumentos de natureza moral (honestidade, probidade, entre outros), passaram a ditar valores a serem seguidos pela sociedade.

Ora, essa condição de superego não foi conquistada instantaneamente, mas é fruto de uma construção institucional que se iniciou no período de constitution-building pré 1988 e encontra-se, ainda, em progresso. Trata-se de verdadeira transformação na distribuição de atribuições e que 
vem sendo paulatinamente construída em verdadeiro equilíbrio dinâmico da separação dos poderes.

Contudo, é preciso ponderar que, quando o Ministério Público como ocorre com o Poder Judiciário - ascende à condição de mais alta instância moral da sociedade, atuando como verdadeiro "superego", passa a escapar de importante mecanismo de controle social (MAUS, 2002, p. 186). Em outras palavras, o Direito, a Política e a Moral encontram-se sujeitos ao crivo de Promotores e Procuradores, seja na atuação extrajudicial, seja no âmbito judicial. A emergência de um Direito "que abarca a própria noção de Moral e Política" faz com que o Ministério Público e os Tribunais Superiores se considerem competentes para controlar o sentido de Constituição e esta passa a ser produto daquilo que Promotores e Procuradores - com a homologação do Judiciário - dizem que é (MAUS, 2002, p. 186).

Veja-se, a título de exemplo, a temática da improbidade administrativa. Hodiernamente, administradores públicos tentam, antes de implantar uma dada política pública ou escolher aqueles que irão assumir cargos de confiança ${ }^{5}$, estabelecer um diálogo com o Ministério Público, objetivando evitar a futura propositura de demanda fundada na Lei n. 8.429/92. Trata-se de verdadeira inversão de papéis: se até então a busca se dava pela jurisprudência sobre o tema, hoje a posição dos membros do Parquet, verdadeiro órgão responsável pelas demandas levadas ao conhecimento do Judiciário, ditam as regras para atuação da Administração Pública, inclusive por meio da expedição de recomendações e celebração de termos de ajustamento de conduta.

Portanto, uma reconstrução da função juspolítica desempenhada pelo Ministério Público apresenta-se oportuna e apropriada para compreender a atuação do órgão no Brasil, objetivando a adoção de medidas extrajudiciais e judiciais racionalmente adequadas com o Estado Democrático de Direito.

\footnotetext{
${ }^{5}$ A título de exemplo, pode-se mencionar a "consulta" que pretendia elaborar a Presidente Dilma Roussef ao Ministério Público para a nomeação de ministros no início do mandato corrente, em razão das repercussões da Operação Lava-Jato.
} 


\section{Por um novo Design Institucional do Ministério Público}

Acreditar que seja possível racionalizar o debate acerca da atuação do Ministério Público, pois, ao invés de ser um defeito - do qual há de se livrar o aplicador do Direito -, o exercício da função juspolítica por Promotores e Procuradores de Justiça constitui-se em uma qualidade essencial, que deve ser exercida sob determinadas balizas.

Anteriormente vinculado ao Executivo, a instituição adquiriu autonomia funcional, distinguindo-se dos demais poderes e passando a exercer a função de imago paterna da sociedade brasileira. Assim, esse novo papel desempenhado pelo Ministério Público vem a demandar um novo desenho institucional capaz de enfrentar com eficiência e dinamismo os desafios impostos à instituição.

Até que ponto a atuação criativa do Promotor cinge-se ao campo jurídico e a partir de que instante esse controle perpassa conteúdos de deliberação eminentemente Política? Qual deve ser o desenho institucional do Ministério Público, responsável por ditar os valores a serem seguidos pela sociedade?

Tradicionalmente, o legislador traça programas e metas pensando nas consequências de suas decisões. Promotores e Juízes se colocam em face dessa seleção prévia, olhando para o caso concreto (LUHMANN, 1985): não trabalham apenas com os interesses políticos e econômicos, mas com os conceitos em que se converteram aqueles interesses, uma vez que o sistema do Direito encontra-se relativamente fechado para o exterior. Daí resulta que o Juiz e o Promotor atuam com fatores jurídicos autorreferenciais transformados em conceitos, os quais são extraídos das leis (DERZI, 2009, p. 27). Já o legislador atua sobre a heterorreferência, criando as leis e conciliando interesses diversos (DERZI, 2009, p. 27).

Nesse liame, o Ministério Público é responsável pelo exercício de parcela significativa do poder político do Estado (ALMEIDA, 2010). A condição de agente político e a conduta independente de seus Membros é instrumento de atuação da própria sociedade, garantindo a efetiva aplicação e a observância da Constituição. Nesse sentido: 
Se a tarefa de elaborar leis é nitidamente política, a de dar efetividade a essas mesmas leis tem, necessariamente, igual dimensão política. Obrigado a zelar pela aplicação da lei, com todas as suas consequências, o Parquet é um órgão estatal cuja atuação repercute diretamente no exercício do poder por todos os atores políticos da sociedade. (LOPES, 1997, p. 96)

Tratando-se de instituição responsável por ditar os valores a serem seguidos pela sociedade, faz-se preciso redesenhar a engenharia institucional até então estabelecida, para que seja possível uma atuação que atente para a verdadeira função do Parquet, com foco na preparação para o exercício eficiente da condição de superego. Ao conceder autonomia funcional aos seus Membros e delegar a Promotores e Procuradores, além da função tradicional no âmbito criminal, a de exigir o cumprimento da lei e a fiscalização de políticas públicas e de direitos coletivos, a instituição passou a desempenhar um novo papel, razão pela qual não pode o desenho institucional permanecer o mesmo.

O Ministério Público do futuro, em grande medida, depende de um novo design institucional e do que fazem hoje seus próprios integrantes, para além das tendências do cenário jurídico. Orientar-se pelas tendências das outras instituições seria perder de vista o que o Ministério Público tem de mais precioso na sua história: os valores ético-morais peculiares de Promotores e de Procuradores que estão ditando o ritmo de toda a sociedade.

O cenário atual, com o sentimento de democratização e o fortalecimento da transparência, é produto da atuação articulada de seus membros e demanda resposta à altura.

Não se pode compactuar, assim, com o teor da revogada Súmula 53, do Conselho Superior do Ministério Público do Estado de São Paulo. É possível observar que:

Não é dever do órgão do Ministério Público instaurar inquérito civil ou outro procedimento investigatório para mero acompanhamento da criação ou execução de programas ou políticas públicas, quando 
não houver notícia concreta de dano ou risco de lesão a interesses difusos, coletivos ou individuais homogêneos ${ }^{6}$.

Como superego da sociedade, o Ministério Público é responsável pela implementação e acompanhamento de políticas públicas, sendo no mínimo contraditório sustentar que pode o Promotor de Justiça deixar de atuar porque não há lesão imediata a bens jurídicos ou pelo fato de que alguns procedimentos não possuem objeto claro e definido. Ao contrário, os Membros do Ministério Público devem assumir verdadeiramente a condição de agentes juspolíticos e passarem a acompanhar os interesses mais lídimos da sociedade, suas reais prioridades e carências mais profundas.

Assim, a juridicização da política e os debates sobre temáticas politicamente carregadas para o Ministério Público decorre da abertura de um espaço em que a deliberação passa a ser "técnica" e "despolitizada", impulsionando, segundo a "filtragem ministerial", o protagonismo do Poder Judiciário e, por via de consequência, minimizando os entraves do processo político. O papel de "superego" está a exigir daquele que tem a função de tutor dos interesses da sociedade que leve em conta as demandas sociais, reivindicando e acompanhando a implementação de políticas públicas, especialmente em searas de reconhecida importância, como a saúde, a educação e a infância.

Para tanto, o Ministério Público precisa promover um novo desenho institucional que afaste a burocratização e promova o interesse público, apresentando-se como abertura de possibilidades a serviço da construção de uma sociedade justa.

Frise-se, por oportuno, que a "racionalização do serviço" não pode ser a lógica adotada pela instituição, uma vez que a redistribuição dos fei-

\footnotetext{
${ }^{6} \mathrm{O}$ Conselho Superior fundamentava a proposta em dois aspectos: 1) o inquérito civil é procedimento destinado a apurar lesão ou ameaça de lesão a direito coletivo em sentido amplo passível de ser tutelado através da ação civil pública, não se justificando impor aos Promotores de Justiça a rigidez procedimental própria do inquérito civil para hipóteses nas quais não há indício de lesão ou ameaça de lesão aos bens jurídicos, cuja defesa incumbe ao Ministério Público; e 2) a instauração de IC ou PPIC para mero acompanhamento de programas ou políticas públicas, não raro, tem resultado em inquéritos civis obscuros ou confusos, que se eternizam sem objeto claro e definido, em prejuízo do serviço.
} 
tos de forma adequada, a partir de um design institucional que privilegia a homogeneidade - e, não, que venha a garantir diferenças entre os diversos cargos existentes - potencializa a produtividade e, consequentemente, o adequado acompanhamento das políticas públicas a serem devolvidas em prol da sociedade. Em outras palavras, é preciso, em primeiro lugar, racionalizar a divisão de trabalho interna da instituição e, apenas em um segundo momento, deixar de atuar em setores indispensáveis para a sociedade.

Não se pode admitir, ainda, o silêncio daquele que atua como superego, uma vez que, desse modo, estará ausente a voz da própria sociedade. A atuação descompromissada, por exemplo, na seara da improbidade administrativa e das políticas públicas, não mais se conforma com o modelo independente e proativo assentado na Constituição, incumbindo-lhe realizar a "filtragem" dos valores a serem seguidos pelos cidadãos, seja por meio do inquérito civil, seja por meio de qualquer outro procedimento de natureza investigatória ou até mesmo pela via jurisdicional. O Ministério Público deve ser capaz de estender uma ponte pelo abismo que separa os discursos éticos, jurídicos e políticos, fomentando uma verdadeira revolução a partir da consciência de seus integrantes, responsáveis por exercer poder político e ditar os valores sociais na permanente construção da Constituição.

Não se pode desconsiderar, nesse liame, nem mesmo a indispensável contribuição trazida pelos mecanismos de governança corporativa. Assim, não apenas se mostra necessária mudança substancial nos ideais e normas que regem a atuação de Promotores e Procuradores de Justiça, mas também a adaptação da estrutura física da instituição, a adoção de políticas internas mais consistentes, a avaliação de desempenho de seus membros e o incentivo à formação continuada dos agentes ministeriais (BIBAS, 2009). O Ministério Público precisa abraçar as novas tecnologias da informação para tornar a atuação de seus membros mais transparente, coerente e responsável, em conformidade com a novo papel que lhe vem sendo conferido pela sociedade (BIBAS, 2009, p. 996).

Por fim, o atendimento ao público e os inúmeros meios disponíveis para a participação do cidadão -como as audiências públicas, as ouvido- 
rias, entre outros - devem ser vistos como importantes manifestações do direito de acesso à justiça social, uma vez que, como responsável por ditar os valores, o Ministério Público deve estar completamente aberto para receber o jurisdicionado e garantir voz àquele que representa.

\section{Conclusão}

Atualmente, o Ministério Público passou a desempenhar tarefas que diversas vezes excedem suas atribuições e que não lhes são, ao menos sob a égide da concepção clássica de separação dos poderes, precípuas.

Ao exercer parcela da autoridade política do Estado, ao realizar a "filtragem" das circunstâncias fáticas no ajuizamento de feitos e diante da função criadora das demandas coletivas, o Ministério Público vem se tornando o último reduto político-moral da sociedade.

A instituição exsurge, nesse liame, com novas atribuições e competências que até então não lhe eram afeitas, aumentando progressivamente seu espaço de atuação, num movimento em que procura substituir funcionalmente a figura da imago paterna, responsável por ditar os valores morais da sociedade, que o Executivo e o Judiciário até então desempenharam.

Nesse contexto, o Ministério Público do futuro, em grande medida, depende de um novo design institucional e do que fazem hoje seus próprios integrantes, para além das tendências do cenário jurídico. Conforme ressaltado, orientar-se pelas tendências das outras instituições seria perder aquilo que a instituição tem de mais precioso: os valores ético-morais de Promotores e Procuradores e que estão ditando o ritmo de toda a sociedade.

Nesse contexto, não se pode desconsiderar a indispensável contribuição trazida pelos mecanismos de governança corporativa, responsáveis pela incorporação de novas tecnologias da informação capazes de tornar a atuação dos membros mais transparente, coerente e responsável.

Em suma, o papel de "superego" está a exigir da instituição que leve em conta as demandas sociais, reivindicando e acompanhando a implementação de políticas públicas. E, para tanto, o Ministério Público precisa promover um novo desenho institucional que afaste a burocrati- 
zação e promova o interesse público, apresentando-se como abertura de possibilidades a serviço da construção de uma sociedade que privilegia o jurisdicionado.

\section{Referências}

ALMEIDA, Fernanda Leão de. A Garantia Institucional do Ministério Público em Função dos Direitos Humanos. 2010. 278 p. Tese (Doutorado em Direito) - Faculdade de Direito, Universidade de São Paulo, São Paulo, 2010.

BANDEIRA DE MELLO, Celso Antônio. Curso de Direito Administrativo. 20. ed. São Paulo: Editora Malheiros, 2006.

BARROSO, Luís Roberto. Interpretação e aplicação da Constituição: fundamentos de uma dogmática constitucional transformadora. São Paulo: Saraiva, 1999.

BERCOVICI, Gilberto. Constituição e Política: uma relação difícil. Lua Nova, São Paulo: Cedec, n. 61, 2004.

BIBAS, Stephanos. Prosecutorial Regulation Versus Prosecutorial Accountability. University of Pennsylvania Law Review, Filadélfia, p. 959-971, 2009.

CAMPILONGO, Celso Fernandes. O Direito na sociedade complexa. São Paulo: Max Limonad, 2000.

CANNARIS, Claus-Wilhelm. Pensamento sistemático e conceito de sistema na Ciência do Direito. Trad. de Antonio Menezes Cordeiro. 2. ed. Lisboa: Fundação Calouste Gulbenkian, 1996.

CANOTILHO, Joaquim José Gomes. Direito Constitucional e Teoria da Constituição. Almedina: Coimbra, 2002.

CORSI, Giancarlo. Sociologia da Constituição. Revista da Faculdade de Direito da Universidade Federal de Minas Gerais. Trad. de Juliana Neuenschwander, Belo Horizonte, n. 39, jan.-jun. 2001. 
COSTA, Rafael de Oliveira. A Criatividade e a Responsabilidade no Ato de Julgar: aportes da Hermenêutica Fenomenológica para a Jurisdição Constitucional. 201 p. 2013. Tese (Doutorado em Direito) - Faculdade de Direito, Universidade Federal de Minas Gerais, Belo Horizonte, 2013.

COSTA, Rafael de Oliveira. Hermenêutica Constitucional e Hermenêutica Filosófica: Horizontes da Previsibilidade das Decisões Judiciais. Direito, Estado e Sociedade, [S.l.], v. 44, p. 122-141, 2014.

DERZI, Misabel Abreu Machado. Modificações da Jurisprudência no Direito Tributário. São Paulo: Noeses, 2009.

DWORKIN, Ronald. Levando os direitos a sério. Trad. Nelson Boeira. São Paulo: Martins Fontes, 2002.

GARCIA, Emerson; ALVES, Rogério Pacheco. Improbidade administrativa. Rio de Janeiro, Lumen Juris, 2011.

JELLINEK, G. Reforma y Mutación de la Constitución. Trad. Christian Förster. Madrid: Centro de Estudios Constitucionales, 1991. KELSEN, Hans. Teoria Pura do Direito. 6. ed. Trad. de João Baptista Machado. São Paulo: Martins Fontes, 1998.

LOPES, João Guimarães. Papel constitucional do Ministério Público. In: CAMARGo ferraZ, Antônio Augusto Mello. Ministério Público: instituição e processo. São Paulo: Atlas, 1997. p. 90-115.

LUHMANN, Niklas. Sistemas sociales: lineamientos para una teoría general. 2. ed. Barcelona: Anthropos, 1998.

LUHMANN, Niklas. Sociologia do Direito I e II. Trad. de Gustavo Bayer. Rio de Janeiro. Tempo Brasileiro,1985.

MAUS, Ingeborg. Judiciário como superego da sociedade: o papel da atividade jurisprudencial na "sociedade órfâ". Revista Novos Estudos CEBRAP, São Paulo, n. 58, p. 183-202, nov. 2002, p. 183-202.

MAUS, Ingeborg. O Direito e a Política: Teoria da Democracia. Belo Horizonte: Del Rey, 2009. 
MAUS, Ingborg. O Judiciário como superego da sociedade. Rio de Janeiro: Lumen Juris, 2010.

NEVES, Marcelo. Transconstitucionalismo. São Paulo: Martins Fontes, 2009.

OLIVEIRA, Márcio Luís de. A Constituição Juridicamente Adequada: transformações do constitucionalismo e atualização principiológica dos direitos, garantias e deveres fundamentais. Belo Horizonte: Arraes, 2013. OSÓRIO, Fábio Medina. Improbidade Administrativa. 2. ed. Porto Alegre: Síntese, 1998.

RADBRUCH, Gustav. Filosofia do direito. Trad. de Cabral de Moncada. 3. ed. Coimbra: Armênio Amado, 1953. V. 1.

SHAPIRO, Martin. Judges As Liars. Harvard Journal of Law and Public Policy, Cambridge, n. 17, p. 155-156, 1994.

TEUBNER, Gunther. O direito como sistema autopoiético. Trad. de José Engrácia Antunes. Lisboa: Fundação Calouste Gulbenkian, 1993.

Rafael de Oliveira Costa é professor visitante na Universidade da CalifórniaBerkeley (EUA) e professor na Escola Superior do Ministério Público do Estado de São Paulo, mestre e doutor em Direito pela Universidade Federal de Minas Gerais (UFMG), graduado em Direito pela UFMG/Universidade de Wisconsin (EUA) e Promotor de Justiça no Estado de São Paulo.

E-mail: rafaelcosta22000@gmail.com.

Endereço profissional: Fórum Oscar Ulson, Rua Bernardino de Campos, n. 770, Centro, Leme, SP - CEP: 13610-901. 